\title{
Activation cross-sections of deuteron induced reactions on natGd up to $50 \mathrm{MeV}$
}

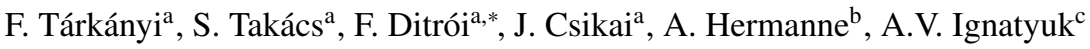 \\ ${ }^{a}$ Institute for Nuclear Research of the Hungarian Academy of Sciences (ATOMKI), Debrecen, Hungary \\ ${ }^{b}$ Cyclotron Laboratory, Vrije Universiteit Brussel (VUB), Brussels, Belgium \\ ${ }^{c}$ Institute of Physics and Power Engineering (IPPE), Obninsk, Russia
}

\begin{abstract}
Activation cross-sections are presented for the first time for ${ }^{n a t} G d(\mathrm{~d}, \mathrm{xn})^{161,160,156(m+), 154,154 m 1,154 m 2,153,152(m+), 151(m+)} T b$, ${ }^{n a t} G d(\mathrm{~d}, \mathrm{x})^{159,153,151} G d$ and ${ }^{n a t} G d(\mathrm{~d}, \mathrm{x})^{156} E u$ reactions from their respective thresholds up to $50 \mathrm{MeV}$. The cross-sections were measured by the stacked-foil irradiation technique and by using high resolution $\gamma$-ray spectrometry. The measured values were compared with the results of theoretical models calculated by the computer codes ALICE-D, EMPIRE-D and TALYS (data from TENDL library). Integral yields of the reaction products were deduced from the excitation functions.
\end{abstract}

Keywords: gadolinium target, terbium, gadolinium and europium radioisotopes, deuteron irradiation, model calculations, physical yield

\section{Introduction}

In a previous paper (Tárkányi et al., 2013) we reported cumulative cross-sections for the formation of medically used ${ }^{161} \mathrm{~Tb}$ radioisotope in the bombardment of ${ }^{n a t} G d$ with deuterons up to $50 \mathrm{MeV}$. In the frame of our ongoing systematic study of deuteron induced reactions for different applications, cross-sections of other radionuclides were also determined during that experiment. Terbium offers four clinically interesting radioisotopes with complementary physical decay characteristics: ${ }^{149} \mathrm{~Tb},{ }^{152} \mathrm{~Tb},{ }^{155} \mathrm{~Tb}$, and ${ }^{161} \mathrm{~Tb}$ (Müller et al., 2012). ${ }^{153} \mathrm{Gd}$ also has extensive use in nuclear medicine. Comparing the results of theoretical model codes with the experimental results, it turned out that the description of the $(\mathrm{d}, \mathrm{p})$ reaction is still problematic for the theory. While the importance of the deuteron induced reaction is rising, the corresponding experimental database is poor compared to that of protons. Taking into account that no earlier data were reported on activation cross-sections of deuteron induced reactions

\footnotetext{
${ }^{*}$ Corresponding author: ditroi@ atomki.hu
}

on Gd, we thought these results have or will have value for applications and for development of nuclear reaction codes. In this paper these excitation functions are presented.

\section{Experiment and data evaluation}

Details of the experimental, as well as the data-analysis procedures, are described in our above mentioned previous work (Tárkányi et al., 2013). For the sake of completeness, the main experimental parameters and methods used for the two performed experiments on Gd are given here (Table 1) (Tárkányi et al., 2001), while the main parameters and data evaluation methods are collected in Table 2 ( Andersen and Ziegler, 1977; Bonardi, 1987, Canberra, 2000, International-Bureau-of-Weightsand-Measures. 1993; Kinsey et al., 1997: Pritychenko and Sonzogni, 2003; Székely, 1985, Tárkányi et al. 1991). The used nuclear data of the produced radioisotopes are presented in Table 3 (NuDat, 2011; Pritychenko and Sonzogni 2003). The figure of the re-measured excitation function of the ${ }^{27} A l(\mathrm{~d}, \mathrm{x})^{24} \mathrm{Na}$ reaction for the high energy irradiation in comparison with the IAEA recommended 
data (Tárkányi et al., 2001) can be found in our earlier publication on Sc, irradiated in the same experiment (Hermanne et al., 2012). The figure of the re-measured excitation function of the ${ }^{n a t} T i(\mathrm{~d}, \mathrm{x})^{48} V$ is not presented here, but the shape and accuracy was the same as published before (Tárkányi et al., 2007).

\section{Model calculations}

For theoretical estimation of the excitation functions involved in this experiment the updated ALICE-IPPED (Dityuk et al., 1998) and EMPIRE-D (Herman et al. 2007) codes were used. In the modified versions of the codes a simulation of direct $(\mathrm{d}, \mathrm{p})$ and $(\mathrm{d}, \mathrm{t})$ transitions by the general relations for a nucleon transfer probability in the continuum is included through an energy dependent enhancement factor for the corresponding transitions based on systematics of experimental data (Ignatyuk, 2011). Since ALICE-IPPE cannot provide direct cross-section results for excited isomeric states, the crosssection for any isomeric state was obtained by applying the isomeric ratios derived from the EMPIRE calculation to the total cross-sections calculated by ALICE-IPPE. The experimental cross-section data were also compared with the results of the modified TALYS code (Koning and Rochman, 2012) taken from the TENDL-2011 and TENDL-2012 data libraries (Koning et al., 2012).

\section{Results and discussion}

\subsection{Cross-sections}

The cross-sections for radionuclides produced in deuteron bombardment of ${ }^{n a t} G d$ target are tabulated in Tables 4 and 5. The experimental cross-section data are compared with the theory graphically in Figs 1-14. The cross-sections given for $160 \mathrm{~Tb}$ and ${ }^{161} \mathrm{~Tb}$ are considered to be isotopic cross-sections as the radionuclides can be induced mainly on ${ }^{160} G d$, as the contribution of $(\mathrm{d}, \gamma)$ reaction on ${ }^{158} G d$ is negligible. In all other cases so called "elemental cross-sections" were deduced on targets with natural isotopic composition. The values for ${ }^{160} \mathrm{~Tb},{ }^{155} \mathrm{~Tb}$, ${ }^{154 m 1} \mathrm{~Tb},{ }^{154 m 2} \mathrm{~Tb},{ }^{154 g} \mathrm{~Tb},{ }^{153} \mathrm{~Tb}$ and in practice also for ${ }^{156} \mathrm{~Tb}$ and ${ }^{156} \mathrm{Eu}$ represent production cross-sections via direct nuclear reactions only. In the cases, where significantly shorter-lived precursors (isomeric states $(\mathrm{m}+)$ and/or parent isotopes (cum)) are also produced, the cross-sections for the ground state were derived from activity measurements performed after the nearly complete decay of the precursor. These cross-sections are hence the sum for the direct production and formation via the decay of the precursors. The values for ${ }^{156} \mathrm{~Tb},{ }^{152} \mathrm{~Tb}$ and ${ }^{151} \mathrm{~Tb}$ contain contribution from the short-lived isomeric states $(\mathrm{m}+)$. Cross-sections are cumulative (cum), with contribution of the decay of parent radionuclides, in case of ${ }^{161} T b,{ }^{159} G d,{ }^{153} G d$ and ${ }^{151} G d$. For the sake of completeness we include the results for the earlier published investigations for production of ${ }^{161} \mathrm{~Tb}$ and ${ }^{160} \mathrm{~Tb}$ both in graphical and in numerical form (Tárkányi et al. 2013).

\subsubsection{Activation cross-sections for production of ${ }^{161} \mathrm{~Tb}$} (cum) $\left(T_{1 / 2}=6.89 d\right)$

We are reproducing the earlier published experimental results (Fig. 1) for production of ${ }^{161} \mathrm{~Tb}$ (cum) (direct, through ${ }^{160} G d(\mathrm{~d}, \mathrm{n})$ and decay of ${ }^{161} G d$ produced by $\left.{ }^{160} G d(\mathrm{~d}, \mathrm{p}){ }^{161} G d\right)$ to illustrate the agreement of the theoretical and experimental data for further discussion. The agreement is acceptable for ALICE-D and EMPIRE-D. The TALYS results are still too low, although the 2012 values are $10 \%$ higher than 2011 values. More detailed discussion on the contributing reactions and on the application of ${ }^{161} \mathrm{~Tb}$ can be found in the previous work (Tárkányi et al., 2013).

\subsubsection{Activation cross-sections for production of ${ }^{160} \mathrm{~Tb}$ $\left(T_{1 / 2}=72.3 d\right)$}

The ${ }^{160} \mathrm{~Tb}$ is produced directly through the ${ }^{160} \mathrm{Gd}(\mathrm{d}, 2 \mathrm{n})$ reaction. Fig. 2 illustrates the prediction capability of the theoretical codes including our ALICE-D and EMPIRE$\mathrm{D}$ results. There are significant differences between the not adjusted theoretical results. There is no difference between TENDL-2011 and TENDL-2012. More detailed discussion was reported in (Tárkányi et al. 2013).

\subsubsection{Activation cross-sections for production of ${ }^{156} \mathrm{~Tb}($ tot $)\left(T_{1 / 2}=5.35 \mathrm{~d}\right)$}

We have measured the production cross-section of the ground state of the ${ }^{156} \mathrm{~Tb}$ (Fig. 3) after the decay of the isomeric states $\left({ }^{156 m 1} \mathrm{~Tb}\right.$, IT: $100 \%, T_{1 / 2}=3 \mathrm{~h}$ and ${ }^{156 m}{ }^{2} \mathrm{~Tb}$, IT: $\left.100 \%, T_{1 / 2}=24.4 \mathrm{~h}\right)$. All theoretical results follow the shape of the experimental excitation function. 
Table 1: Main experimental parameters

\begin{tabular}{|c|c|c|}
\hline Incident particle & Deuteron & Deuteron \\
\hline Method & Stacked foil & Stacked foil \\
\hline \multirow[t]{3}{*}{ Target composition } & ${ }^{n a t} \mathrm{Gd}(83.9 \mu \mathrm{m})$ & ${ }^{n a l}{ }_{\mathrm{Gd}}(83.9 \mu \mathrm{m})$ \\
\hline & $\mathrm{Al}(98 \mu \mathrm{m})$ & $\mathrm{Sc}(105 \mu \mathrm{m})$ \\
\hline & $\operatorname{Ti}(11 \mu \mathrm{m})$ & $\mathrm{Al}(27 \mu \mathrm{m})$ \\
\hline Number of Gd targetfoils & 9 & 20 \\
\hline Accelerator & $\begin{array}{l}\text { CGR } 560 \text { cyclotron of Vrije Universiteit Brus- } \\
\text { sels }\end{array}$ & $\begin{array}{l}\text { Cyclone } 90 \text { cyclotron of the UniversitCatholique in } \\
\text { Louvain la Neuve (LLN) }\end{array}$ \\
\hline Nominal energy & $21 \mathrm{MeV}$ & $50 \mathrm{MeV}$ \\
\hline Irradiation time & $110 \mathrm{~min}$ & $42 \mathrm{~min}$ \\
\hline Beam current (in Faraday) & $60 \mathrm{nA}$ & $115 \mathrm{nA}$ \\
\hline Monitor reaction, [recommended values] & $\begin{array}{l}{ }_{n a t} \mathrm{Ti}(\mathrm{d}, \mathrm{x})^{48} \mathrm{~V} \text { reaction } \\
\text { (re-measured overnyi et al. } 2001\end{array}$ & 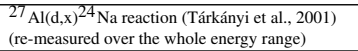 \\
\hline Monitor target and thickness & ${ }^{{ }^{n a l}} \mathrm{Ti}, 11 \mu \mathrm{m}$ & ${ }^{n a t} \mathrm{Al}, 27 \mu \mathrm{m}$ \\
\hline detector & HpGe & HpGe \\
\hline Chemical separation & no & no \\
\hline $\mathrm{g}$-spectra measurements & 2 series & 3 series \\
\hline Cooling times & $\begin{array}{l}1.5-4.6 \mathrm{~h}, \\
260-269 \mathrm{~h}\end{array}$ & $\begin{array}{l}2.2-5.3 \mathrm{~h}, \\
20-27 \mathrm{~h}, \\
197-227 \mathrm{~h}\end{array}$ \\
\hline
\end{tabular}

Table 2: Main parameters and methods of the data evaluation (with references)

\begin{tabular}{|c|c|c|}
\hline Parameter & Method & Reference \\
\hline Gamma spectra evaluation & Genie 2000, Forgamma & Canberra. 2000 Székely. 1985 \\
\hline Determination of beam intensity & $\begin{array}{l}\text { Faraday cup (preliminary) } \\
\text { Fitted monitor reaction (final) }\end{array}$ & Tarkanyi et al. 1991 \\
\hline Decay data (see Table 3) & NUDAT 2.6 & Kinsey et al. 1997] \\
\hline Reaction Q-values(see Table 3) & Q-value calculator & (Pritychenko and Sonzogni, 2003) \\
\hline Determination of beam energy & $\begin{array}{l}\text { Andersen (preliminary) } \\
\text { Fitted monitor reaction (final) }\end{array}$ & $\begin{array}{l}\text { Andersen and Ziegler, } 1977 \\
\text { Tárkányi et al. 1991? }\end{array}$ \\
\hline Uncertainty of energy & $\begin{array}{l}\text { Cumulative effects of possible uncertainties } \\
\text { (nominal energy, target thickness, energy straggling, correction to moni- } \\
\text { tor reaction) }\end{array}$ & \\
\hline Cross-sections & Isotopic and elemental cross-sections & \\
\hline Uncertainty of cross-sections & $\begin{array}{l}\text { sum in quadrature of all individual contributions } \\
\text { beam-current }(7 \%) \\
\text { beam-loss corrections ( } \max .1 .5 \%) \\
\text { target thickness }(1 \%) \\
\text { detector efficiency }(5-7 \%) \\
\text { photo peak area determination and } \\
\text { counting statistics }(1-20 \%)\end{array}$ & $\begin{array}{l}\text { (International-Bureau-of-Weights-and-Measures, } \\
\text { 1993) }\end{array}$ \\
\hline Yield & Physical yield & Bonardi 1987] \\
\hline
\end{tabular}

The EMPIRE-D results are significantly overestimating the experimental values (similar to the previous reaction).

\subsubsection{Activation cross-sections for production of ${ }^{155} \mathrm{~Tb}$} $\left(T_{1 / 2}=5.32 d\right)$

According to Fig. 4 the ALICE-D and EMPIRE-D significantly overestimate the experimental data, while the TENDL results (nearly identical for 2011 and 2012) are in good accordance.

\subsubsection{Activation cross-sections for production of ${ }^{154 m 2} \mathrm{~Tb}$ $\left(T_{1 / 2}=22.7 \mathrm{~h}\right)$}

The ${ }^{154} \mathrm{~Tb}$ has three, long-lived isomeric states. The cross-sections for direct production of the higher lying isomer $\left(T_{1 / 2}=22.7 \mathrm{~h}, J^{\pi}=7^{-}, \varepsilon^{+}+\beta^{+} 98.2 \%\right.$, IT $1.8 \%$ to the ${ }^{154 m 1} \mathrm{~Tb}$ (Ekstrm and Firestone, 1999)) are shown in Fig. 5 in comparison with the theoretical result of EMPIRE-D and ALICE-D. No data are available in the TENDL libraries for production of this isomeric state.

\subsubsection{Activation cross-sections for production of ${ }^{154 m 1} \mathrm{~Tb}$ $\left(T_{1 / 2}=9.4 \mathrm{~h}\right)$}

The cross-section of the second (lower-lying) isomeric state $\left(9.4 \mathrm{~h}, J^{\pi}=3^{-}, \varepsilon^{+}+\beta^{+}+78.2 \%\right.$, IT $21.8 \%$ to ${ }^{154 g} \mathrm{~Tb}$ (Ekstrm and Firestone, 1999) $)$ is shown in Fig. 6. It should be noted that there are new data for the half-life (9.994 h (Rastrepina, 2009), but it is not validated, therefore we used $T_{1 / 2}=9.4 \mathrm{~h}$. The ${ }^{154 m 1} \mathrm{~Tb}$ is produced both 


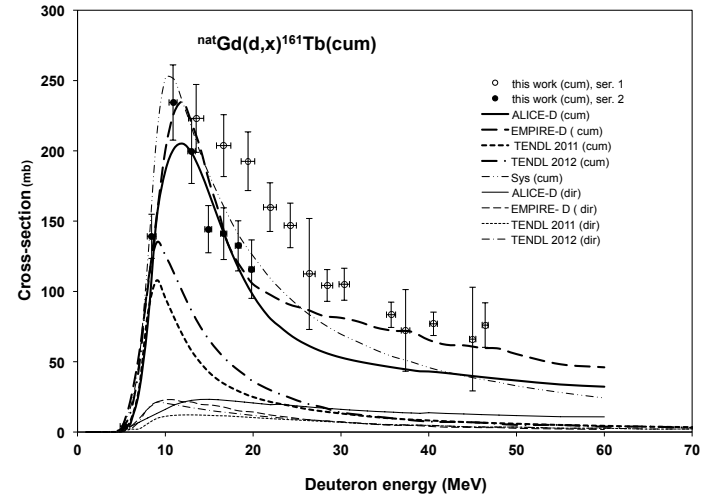

Figure 1: Experimental and theoretical excitation functions of the ${ }^{\text {nat }} \mathrm{Gd}(\mathrm{d}, \mathrm{x})^{161} \mathrm{~Tb}$ reaction

directly and from the decay of ${ }^{154 m 2} \mathrm{~Tb}$. The contribution from the decay of ${ }^{154 m 2} \mathrm{~Tb}$ was corrected. The correction was small taking into account the low cross-sections and the low amount of the internal transition. The excitation function is shown in Fig 6 in comparison with the theory. The experimental data are significantly higher than the theoretical results. During our EMPIRE-D calculation some problems arose with the level scheme of ${ }^{154} \mathrm{~Tb}$. There are no experimental data for the low-lying levels around the isomeric states. As such, the scheme used in calculations is artificial and based on the systematics of levels of the neighboring nuclei.

\subsubsection{Activation cross-sections for production of ${ }^{154 g} \mathrm{~Tb}(\mathrm{ml}+)\left(T_{1 / 2}=21.5 \mathrm{~h}\right)$}

By using the late spectra we can deduce cumulative cross-sections for production of the ground state after the complete decay of the ${ }^{154 m 1} \mathrm{~Tb}$ (Fig. 7). The contribution of the decay of ${ }^{154 m} 2 \mathrm{~Tb}$ to the production of the ground state is negligibly small compared to the direct production and to the contribution from the first isomeric state. The experimental data are systematically higher than the results of the EMPIRE-D. No data exist in the TENDL libraries for the isomeric states, only for the total production.

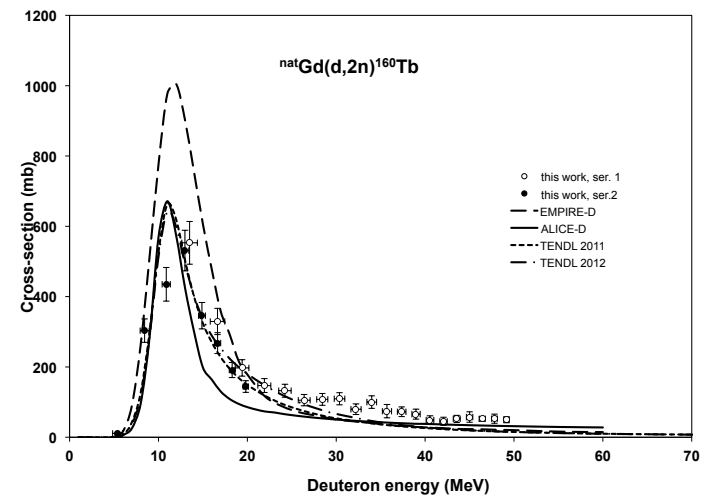

Figure 2: Experimental and theoretical excitation function of the ${ }^{\text {nat }} G d(\mathrm{~d}, 2 \mathrm{n}){ }^{160} \mathrm{~Tb}$ reaction

\subsubsection{Activation cross-sections for production of ${ }^{153} \mathrm{~Tb}$ $\left(T_{1 / 2}=2.34 d\right)$}

The agreement with the TENDL results is good (Fig. 8). There are large differences in the absolute values of the predictions by ALICE-D and EMPIRE-D at energies above $30 \mathrm{MeV}$.

\subsubsection{Activation cross-sections for production of ${ }^{152} \mathrm{~Tb}$ $(m+)\left(T_{1 / 2}=17.5 \mathrm{~h}\right)$}

The excitation function was measured after the decay of the short-lived isomeric state (4.2 min, IT: $78.8 \%$ ). The agreement with the TENDL library results (Fig. 9) is good, while ALICE-D and EMPIRE-D strongly overestimate again above $40 \mathrm{MeV}$.

\subsubsection{Activation cross-sections for production of ${ }^{151} \mathrm{~Tb}$ $(\mathrm{m}+)\left(T_{1 / 2}=17.609 \mathrm{~h}\right)$}

The measured excitation function contains the contribution from the decay of the short-lived isomeric state $(25$ s, IT: $93.4 \%)$. Above $35 \mathrm{MeV}$ all theoretical predictions overestimate the experimental values (Fig. 10).

\subsubsection{Activation cross-sections for production of ${ }^{159} \mathrm{Gd}$ $\left(T_{1 / 2}=18.479 \mathrm{~h}\right)$}

There are two maxima in the measured excitation function of ${ }^{n a t} G d(\mathrm{~d}, \mathrm{x}){ }^{159} G d$ (Fig. 11). The first comes from 


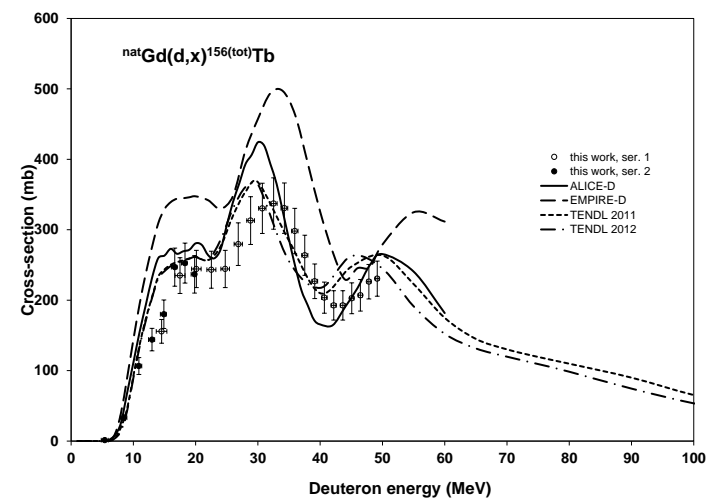

Figure 3: Experimental and theoretical excitation function of the ${ }^{n a t} G d(\mathrm{~d}, \mathrm{x}){ }^{156} \mathrm{~Tb}(\mathrm{~m}+)$ reaction

the ${ }^{158} G d(\mathrm{~d}, \mathrm{p}){ }^{159} G d$ reaction and the second from nuclear reactions on ${ }^{160} G d$, namely from ${ }^{160} G d(\mathrm{~d}, \mathrm{p} 2 \mathrm{n}){ }^{159} G d$ and from the $\beta^{-}$-decay of ${ }^{159} E u(18.1 \mathrm{~min})$, produced via ${ }^{160} G d(\mathrm{~d}, 2 \mathrm{pn}){ }^{159} E u$ reaction. The TENDL data significantly underestimate the ${ }^{158} G d(\mathrm{~d}, \mathrm{p}){ }^{159} G d$ reaction, while by ALICE-D and EMPIRE-D (where in the D-versions the $(d, p)$ reaction is enhanced) the higher energy peak is lower than the experiment and the TENDL value.

\subsubsection{Activation cross-sections for production of ${ }^{153} \mathrm{Gd}(\mathrm{cum})\left(T_{1 / 2}=240.4 d\right)$}

The measured excitation function of ${ }^{153} G d(240.4 \mathrm{~d})$ (Fig. 12) was deduced from spectra measured nearly 10 days after EOB, i.e. after five half-lives of the parent ${ }^{153} \mathrm{~Tb}(2.34 \mathrm{~d})$. In these measuring conditions only around $3 \%$ from the decay of ${ }^{153} \mathrm{~Tb}$ was missing. The missing part was corrected on the basis of the measured crosssection of ${ }^{153} \mathrm{~Tb}$. The three codes result in acceptable predictions.

\subsubsection{Activation cross-sections for production of ${ }^{151} \mathrm{Gd}$ $\left(T_{1 / 2}=123.9 d\right)$}

The cumulative cross-sections include the complete decay of ${ }^{151} \mathrm{~Tb}$ (17.609 h) (Fig. 13). The results of the model calculations generally run together in the investigated en-

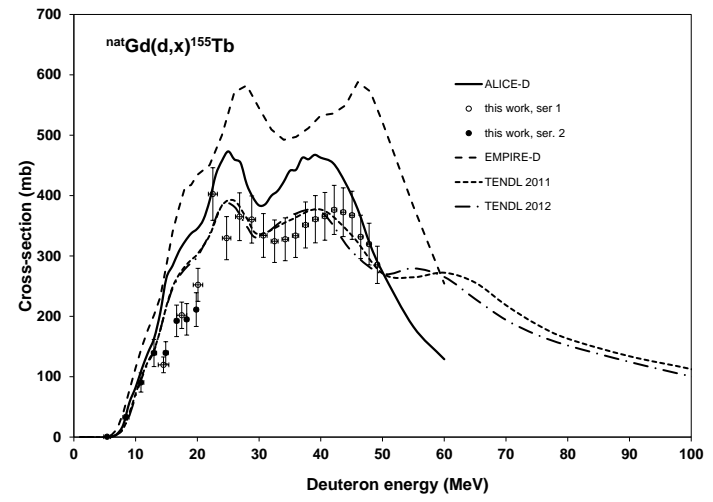

Figure 4: Experimental and theoretical excitation function of the ${ }^{n a t} G d(\mathrm{~d}, \mathrm{x}){ }^{155} \mathrm{~Tb}$ reaction

ergy range, but they more or less overestimate the experimental values.

\subsubsection{Activation cross-sections for production of ${ }^{156} \mathrm{Eu}$ $\left(T_{1 / 2}=15.19 d\right)$}

In the investigated energy range ${ }^{156} E u$ is produced mostly via $(\mathrm{d}, \alpha \mathrm{xn})$ reactions. The contribution from the parent $156 \mathrm{Sm}\left(9.4 \mathrm{~h}, \beta^{-}\right)$is small due to the low crosssections expected for the (d,3pxn) reactions (Fig. 14).

\subsection{Integral yields}

From fits to our experimental excitation functions thick target physical yields (instantaneous short irradiation) were calculated. The integral yields are shown in Fig. 15-16 in comparison with the directly measured data (Dmitriev et al., 1982, 1989). The agreement with the existing experimental values for ${ }^{155} \mathrm{~Tb}$ and ${ }^{156} \mathrm{~Tb}$ is acceptable (Fig. 15).

\section{Comparison of the production routes of the ${ }^{153} \mathrm{Gd}$}

${ }^{153} G d(240.4 \mathrm{~d})$ emits two low-energy photons with energies of $97.43 \mathrm{keV}$ and $103.18 \mathrm{keV}$ respectively, which are optimal to penetrate through the body, expose the patient only to limited dose and can be detected with standard imaging technology. The ${ }^{153} G d$ is used in nuclear 


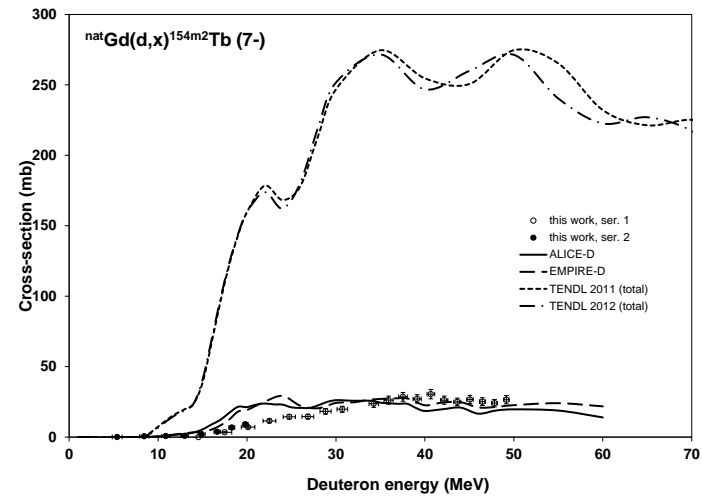

Figure 5: Experimental and theoretical excitation function of the ${ }^{n a t} G d(\mathrm{~d}, \mathrm{x}){ }^{154 m 2} \mathrm{~Tb}$ reaction

medicine for attenuation corrections by means of additional $\gamma$-transmission measurements (Van Laere et al. 2000), for determination of the bone mineral content (Smith et al., 1983), for labeling gadolinium-based contrast agent (Wadas et al., 2010) as well as for localizing sentinel lymph nodes (Liu et al., 2013). The long-lived radionuclide ${ }^{153} G d$ can be produced via various nuclear reactions. Taking into account the long half-life, the traditional way is using parallel production by neutron induced reactions at research reactors. A few neutron induced production routes were previously investigated and reported in the literature:

- $\left.{ }^{151} E u(\mathrm{n}, \gamma){ }^{152} E u \longrightarrow{ }^{152} G d(n, \gamma)\right)^{153} G d(?)$

- ${ }^{152} G d(\mathrm{n}, \gamma)$ on highly enriched ${ }^{152} G d$ (Case et al. 1969)

- ${ }^{156} \operatorname{Dy}(\mathrm{n}, \alpha){ }^{153} G d$ reaction (?)

The first two methods result in carrier added product, but by using high flux reactors and long irradiations the specific activity can be rather high. The $(\mathrm{n}, \alpha)$ reaction $(\mathrm{Q}=$ $8.006 \mathrm{MeV}$ ) results in no-carrier added product, but the yield is also low. There are various production routes using charged particle accelerators for production of no carrier added ${ }^{153} G d$ :

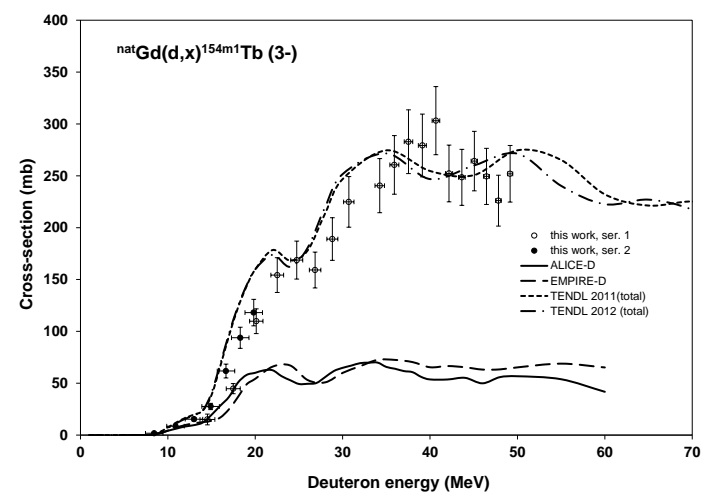

Figure 6: Experimental and theoretical excitation function of the ${ }^{n a t} \mathrm{Gd}(\mathrm{d}, \mathrm{x})^{154 m 1} \mathrm{~Tb}$ reaction

- Spallation reactions using mass separators (Beyer and Ruth, 2003)

- Low energy light ion induced reactions

By using light ion induced reactions the ${ }^{153} G d$ (240.4 d) can be produced directly or through the decay of the ${ }^{153} \mathrm{~Tb}(2.34 \mathrm{~d})$. The most important direct and indirect reactions, together with the possible disturbing reactions are collected in Table 6. For the ${ }^{153} E u(\mathrm{p}, \mathrm{n}){ }^{153} G d$ and ${ }^{153} E u(\mathrm{~d}, 2 \mathrm{n}){ }^{153} G d$ nuclear reactions experimental excitation functions are available (West et al., 1993). For other reactions the TALYS data from the TENDL-2012 library are presented. For comparison, the predictive force of the TENDL data is satisfactory (see also Fig. 12), taking into account the resulted large differences in the production yields of the different production routes. The ${ }^{153} E u(\mathrm{p}, \mathrm{n})$ and ${ }^{153} E u(\mathrm{~d}, 2 \mathrm{n})$ reactions result in direct production. After irradiation the $\mathrm{Gd}$ can be separated from the target. In the case of ${ }^{154} G d(\mathrm{p}, 2 \mathrm{n}){ }^{153} \mathrm{~Tb} \longrightarrow{ }^{153} \mathrm{Gd}$, ${ }^{154} \mathrm{Gd}(\mathrm{d}, 3 \mathrm{n}){ }^{153} \mathrm{~Tb} \longrightarrow{ }^{153} \mathrm{Gd},{ }^{151} E u(\alpha, 2 \mathrm{n}){ }^{153} \mathrm{~Tb} \longrightarrow{ }^{153}$ $G d$ and ${ }^{151} \mathrm{Eu}\left({ }^{3} \mathrm{He}, \mathrm{n}\right){ }^{153} \mathrm{~Tb} \longrightarrow{ }^{153} \mathrm{Gd}$ routes the production is indirect, the produced ${ }^{153} \mathrm{~Tb}$ must be separated at the end of the irradiation from the Gd or Eu target to assure no carrier added final product. The excitation functions are shown on Fig. 17. In all cases, from the point of view of radionuclidic purity, the production of the ${ }^{151} G d$ 


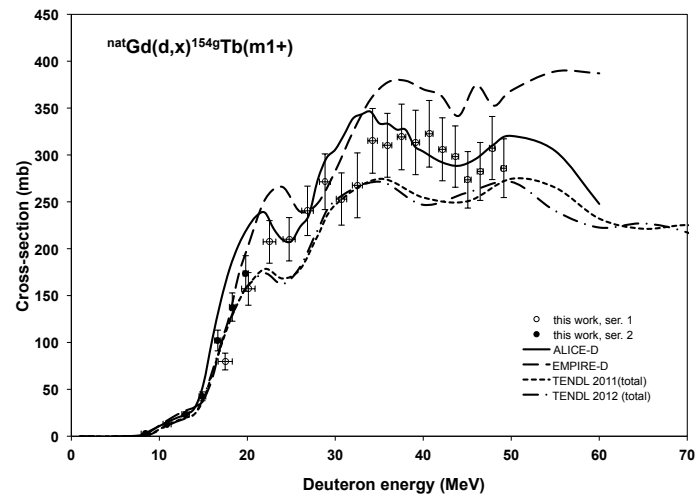

Figure 7: Experimental and theoretical excitation function of the ${ }^{n a t} G d(\mathrm{~d}, \mathrm{x}){ }^{154 g} \mathrm{~Tb}(\mathrm{~m} 1+)$ reaction

(120 d) and consequently also its parent ${ }^{151} \mathrm{~Tb}(17.609 \mathrm{~h})$ should be eliminated, which gives an upper limit for the energy of the bombarding beam (see the energy windows in Table 6). The comparison of the productivity for different charged particle induced reaction shows that in the case of direct production the deuterons are more favorable (a factor of 3, see Table 6). The energy windows were chosen in such a way that the production and target preparation is optimal, based on the cross-sections, thresholds of the disturbing reactions and also on experimental experiences. In the case of indirect production however, the protons are slightly more favorable. The yield of the alpha-particle induced reaction is significantly less than that of the deuteron induced reactions. The yield of the ${ }^{3} \mathrm{He}$ route is negligible $(\max =1.5 \mathrm{mb}, \mathrm{Y}=104 \mathrm{MBq} / \mathrm{C})$. The indirect proton and deuteron yields are comparable, the proton irradiation yields $20 \%$ more ${ }^{153} \mathrm{Gd}$, and it must also be mentioned that less accelerators can provide 30 $\mathrm{MeV}$ deuteron energy. There are many other factors determining the final competitivity of the different production routes:

- Taking into account the long half-life of ${ }^{153} \mathrm{Gd}$, long irradiations are necessary to produce reasonable activities, which is straightforward in the case of direct reactions. Using the indirect route the half-life of the ${ }^{153} \mathrm{~Tb}$ limits the length of a single irradiation. More-

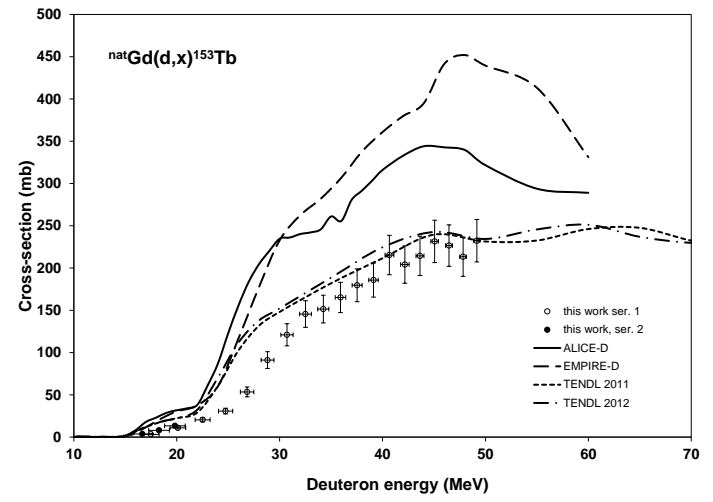

Figure 8: Experimental and theoretical excitation function of the ${ }^{n a t} G d(\mathrm{~d}, \mathrm{x}){ }^{153} \mathrm{~Tb}$ reaction

over, the repeated separation causes losses in the expensive enriched target material

- The price of the highly enriched ${ }^{153} \mathrm{Eu}$ is significantly lower compared to that of highly enriched ${ }^{154} G d$

- In general, cyclotrons have significantly lower beam intensities for d-, $\alpha$ - and ${ }^{3} \mathrm{He}$-particle beams compared to protons

There are other important factors, when one compares with the production routes at research reactors.

- The long half-life requires long irradiations. The most economical way of it is simultaneous parasitic irradiation (dividing the beam), which in case of low and medium energy cyclotrons is not a simple task (cooling problems, target construction, etc.), but in the case of reactors it is an everyday practice

- The cross-sections of the (n, $\gamma)$ reactions are significantly higher compared to the charged particle induced reactions

- In case of neutrons large mass targets can be used, without beam stopping and cooling problems 


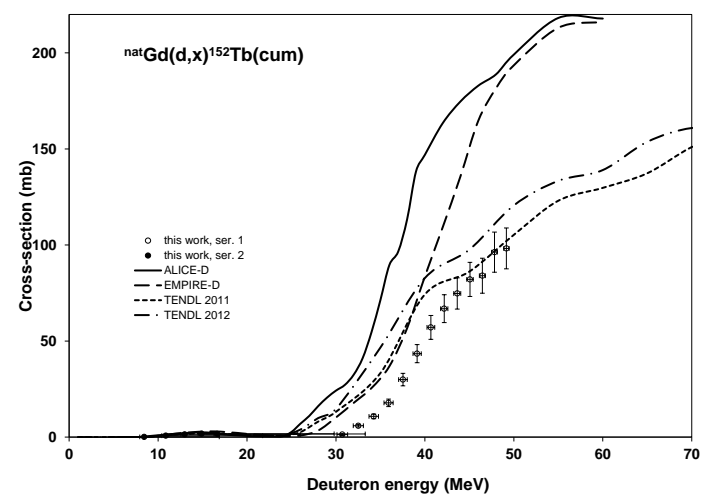

Figure 9: Experimental and theoretical excitation function of the ${ }^{n a t} \mathrm{Gd}(\mathrm{d}, \mathrm{x}){ }^{152} \mathrm{~Tb}(\mathrm{~m}+)$ reaction

By summarizing the above mentioned factors, it can be concluded that it is very difficult to compete with the reactor production. The charged particle routes can only be used for production of small amounts for research purposes.

\section{Summary and conclusions}

This work was performed in the frame of the systematic study of activation cross-sections for applications and for development of the nuclear reaction model codes. In this study experimental cross-sections for the ${ }^{n a t} \mathrm{Gd}(\mathrm{d}, \mathrm{xn})^{161,160,156(m+), 154,154 m 1,154 m 2,153,152(m+), 151(m+)} \mathrm{Tb}$, ${ }^{n a t} G d(\mathrm{~d}, \mathrm{xn}){ }^{159,153,151} G d$ and ${ }^{n a t} G d(\mathrm{~d}, \mathrm{x}){ }^{156} E u$ nuclear reactions were measured up to $50 \mathrm{MeV}$. Comparison of the experimental and theoretical results calculated by the ALICE-D EMPIRE-D and TALYS codes shows that still significant disagreements between the theoretical predictions and the existing experimental data. The empirical improvement of the deuteron breakup description, which was a serious problem by the original EMPIRE and ALICE codes by describing deuteron induced reactions, has improved the predictions in the EMPIRE-D and ALICE-D codes. Among the studied reaction products ${ }^{161} \mathrm{~Tb}$ and ${ }^{153} \mathrm{Gd}$ are of importance for nuclear medicine. In order to prepare a carrier free ${ }^{161} \mathrm{~Tb}$ end product the

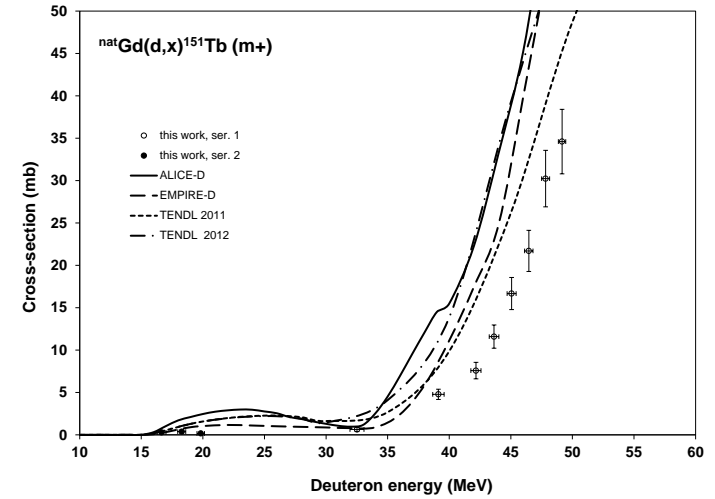

Figure 10: Experimental and theoretical excitation function of the ${ }^{n a t} \mathrm{G} d(\mathrm{~d}, \mathrm{x}){ }^{151} \mathrm{~Tb}(\mathrm{~m}+)$ reaction

${ }^{160} G d(\mathrm{n}, \quad){ }^{161} G d{ }^{161} T b$ route is more productive than ${ }^{160} G d(\mathrm{~d}, \mathrm{n}){ }^{161} T b+{ }^{160} G d(\mathrm{~d}, \mathrm{p}){ }^{161} G d \longrightarrow{ }^{161} T b$ (Tárkányi et al. 2013). According to our comparison of production routes of carrier free ${ }^{153} G d$ (this work) the deuteron induced reactions on $\mathrm{Eu}$ and $\mathrm{Gd}$ are competitive with proton induced reactions in special cases concerning to yields, but because of the availability of the required deuteron energy and intensity, the proton induced reaction is more favorable.

\section{Acknowledgements}

This work was performed in the frame of the HASFWO Vlaanderen (Hungary-Belgium) project. The authors acknowledge the support of the research project and of the respective institutions. We are grateful to all the authorities concerned. We thank to the Cyclotron Laboratory of the Universit Catholique in Louvain la Neuve (LLN) providing the beam time and the staff of the LLN Cyclone 90 cyclotron for performing the irradiations. 


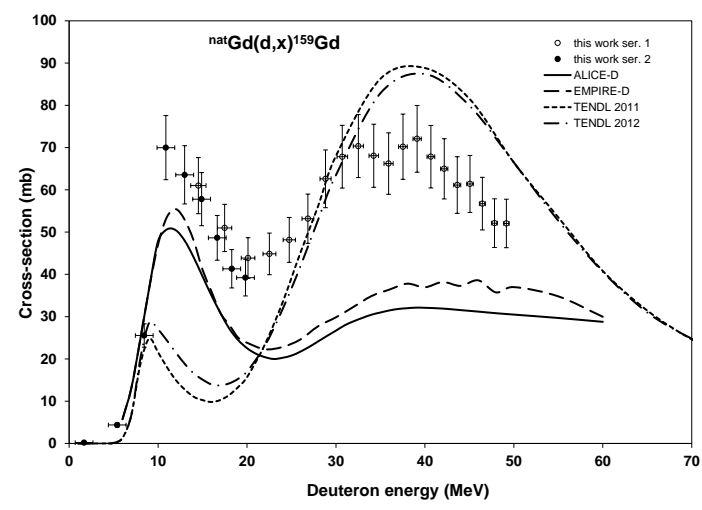

Figure 11: Experimental and theoretical excitation function of the ${ }^{n a t} G d(\mathrm{~d}, \mathrm{x}){ }^{159} G d$ reaction

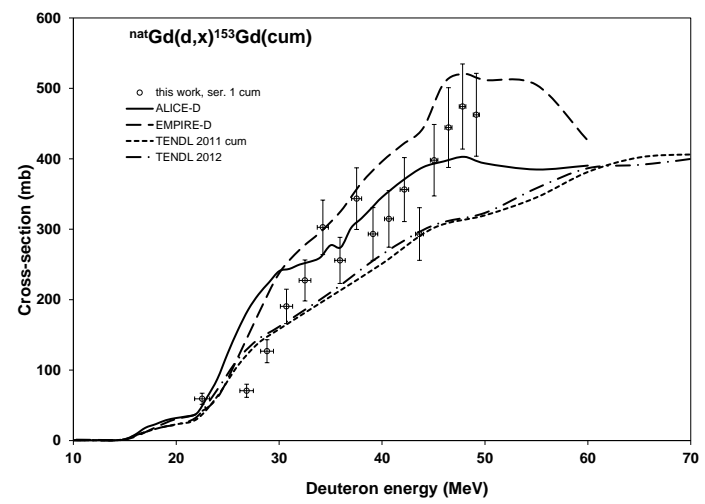

Figure 12: Experimental and theoretical excitation function of the ${ }^{n a t} G d(\mathrm{~d}, \mathrm{x})^{153} G d(\mathrm{cum})$ reaction

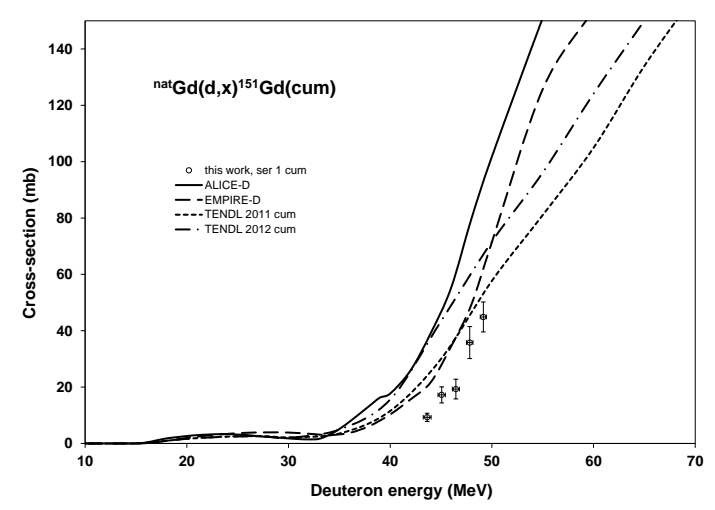

Figure 13: Experimental and theoretical excitation function of the ${ }^{n a t} G d(\mathrm{~d}, \mathrm{x}){ }^{151} G d$ (cum) reaction

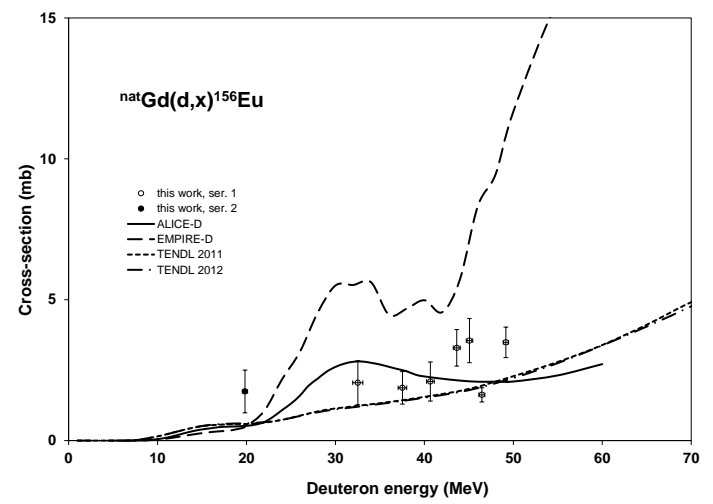

Figure 14: Experimental and theoretical excitation function of the ${ }^{n a t} G d(\mathrm{~d}, \mathrm{x}){ }^{156} E u$ reaction 


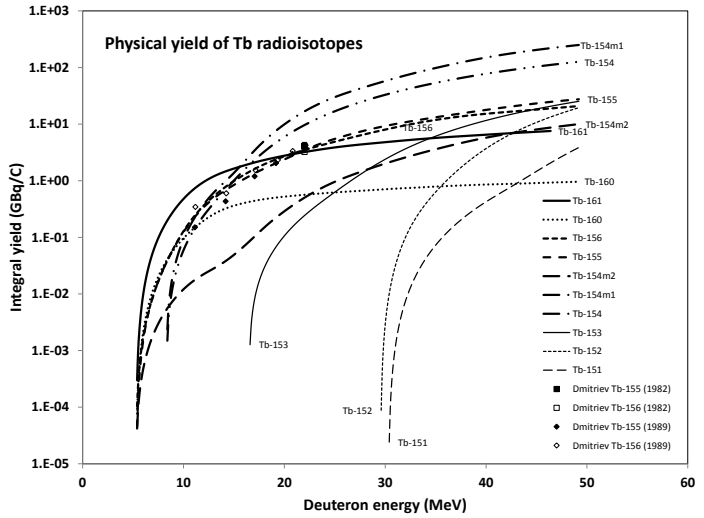

Figure 15: Calculated integral yields of $\mathrm{Tb}$ radioisotopes on natural gadolinium as a function of the energy

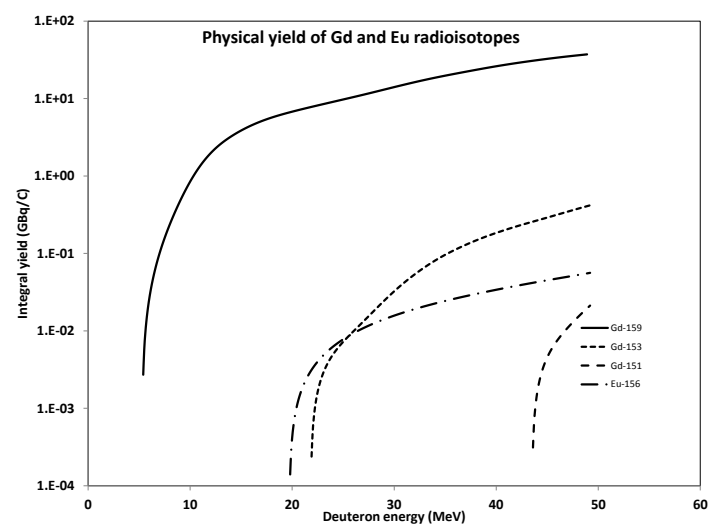

Figure 16: Calculated integral yields of Gd and Eu radioisotopes on natural gadolinium as a function of the energy

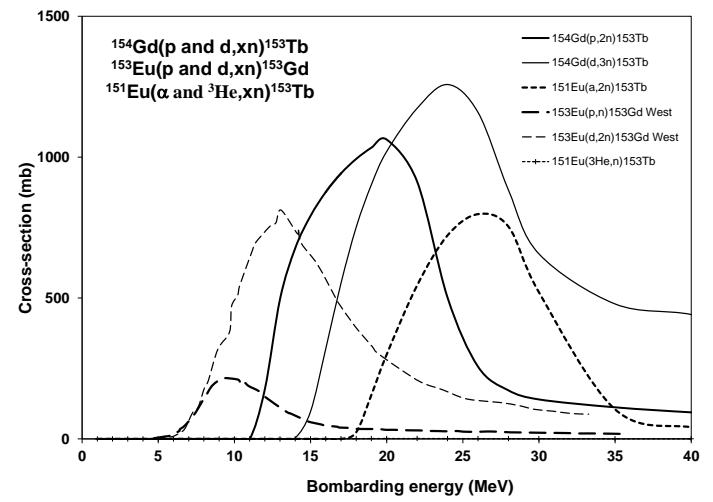

Figure 17: Comparison of the excitation functions of the light ion induced production routes of ${ }^{153} \mathrm{Gd}$ and ${ }^{153} \mathrm{~Tb}$ by using literature data or model calculations 
Table 3: Decay characteristic and contributing reactions for production of ${ }^{161,160,156(m+), 154,154 m 1,154 m 2,153,152,151} \mathrm{~Tb},{ }^{159,153,151} \mathrm{Gd},{ }^{56} \mathrm{Eu}$

\begin{tabular}{|c|c|c|c|c|c|}
\hline $\begin{array}{l}\text { Nuclide } \\
\text { Decay mode }\end{array}$ & Half-life & $\mathrm{E}_{\gamma}(\mathrm{keV})$ & $\mathrm{I}_{\gamma(\%)}$ & Contributing reaction & $\begin{array}{l}\text { Q-value } \\
(\mathrm{keV})\end{array}$ \\
\hline $\begin{array}{l}{ }^{161} \mathbf{T b} \\
\beta^{-}: 100 \%\end{array}$ & $6.89 \mathrm{~d}$ & $\begin{array}{l}25.65135 \\
48.91533 \\
57.1917 \\
74.56669 \\
\end{array}$ & $\begin{array}{l}23.2 \\
17.0 \\
1.79 \\
10.2 \\
\end{array}$ & $\begin{array}{l}160 \mathrm{Gd}(\mathrm{d}, \mathrm{n}) \\
{ }^{160} \mathrm{Gd}(\mathrm{d}, \mathrm{p}){ }^{161} \mathrm{Gd}^{161} \mathrm{~Tb}\end{array}$ & $\begin{array}{l}4584.3 \\
3410.83\end{array}$ \\
\hline $\begin{array}{l}{ }^{160} \mathbf{T b} \\
\beta^{-}: 100 \%\end{array}$ & $72.3 \mathrm{~d}$ & $\begin{array}{l}86.7877 \\
197.0341 \\
215.6452 \\
298.5783 \\
879.378 \\
962.311 \\
966.166 \\
1177.954\end{array}$ & $\begin{array}{l}13.2 \\
5.18 \\
4.02 \\
26.1 \\
30.1 \\
9.81 \\
25.1 \\
14.9\end{array}$ & ${ }^{160} \mathrm{Gd}(\mathrm{d}, 2 \mathrm{n})$ & -3112.31 \\
\hline $\begin{array}{l}{ }^{156} \mathbf{T b} \\
\varepsilon: 100 \%\end{array}$ & $5.35 \mathrm{~d}$ & $\begin{array}{l}88.97 \\
199.19 \\
262.54 \\
296.49 \\
356.38 \\
422.34 \\
534.29 \\
1065.11 \\
1154.07 \\
1159.03 \\
1222.44 \\
1421.67\end{array}$ & $\begin{array}{l}18.0 \\
41.0 \\
5.8 \\
4.5 \\
13.6 \\
8.0 \\
67 \\
10.8 \\
10.4 \\
7.2 \\
31 \\
12.2\end{array}$ & $\begin{array}{l}{ }^{155} \mathrm{Gd}(\mathrm{d}, \mathrm{n}) \\
156 \mathrm{Gd}(\mathrm{d}, 2 \mathrm{n}) \\
157 \mathrm{Gd}(\mathrm{d}, 3 \mathrm{n}) \\
158_{\mathrm{Gd}(\mathrm{d}, 4 \mathrm{n})} \\
160 \mathrm{Gd}(\mathrm{d}, 6 \mathrm{n})\end{array}$ & $\begin{array}{l}3085.25 \\
-5451.1 \\
-11810.96 \\
-19748.35 \\
-33143.03\end{array}$ \\
\hline $\begin{array}{l}155 \mathbf{T b} \\
\varepsilon: 100 \%\end{array}$ & $5.32 \mathrm{~d}$ & $\begin{array}{l}86.55 \\
105.318 \\
148.64 \\
161.29 \\
163.28 \\
180.08 \\
340.67 \\
367.36\end{array}$ & \begin{tabular}{l|}
32.0 \\
25.1 \\
2.65 \\
2.76 \\
4.44 \\
7.5 \\
1.18 \\
1.48
\end{tabular} & $\begin{array}{l}154 \mathrm{Gd}(\mathrm{d}, \mathrm{n}) \\
155_{\mathrm{Gd}(\mathrm{d}, 2 \mathrm{n})} \\
156_{\mathrm{Gd}(\mathrm{d}, 3 \mathrm{n})} \\
157 \mathrm{Gd}(\mathrm{d}, 4 \mathrm{n}) \\
158 \mathrm{Gd}(\mathrm{d}, 5 \mathrm{n}) \\
160 \mathrm{Gd}(\mathrm{d}, 7 \mathrm{n})\end{array}$ & $\begin{array}{l}2608.53 \\
-3826.7 \\
-12363.0 \\
-18722.9 \\
-26660.3 \\
-40055.0\end{array}$ \\
\hline $\begin{array}{l}154 m \mathrm{l} \mathbf{T b} \\
\mathrm{e}^{+}+\mathrm{b}^{+}(78.2 \%) \\
\operatorname{IT}(21.8 \%)\end{array}$ & $9.4 \mathrm{~h}$ & $\begin{array}{l}518.011 \\
540.18 \\
649.564 \\
873.190 \\
996.262 \\
1004.725\end{array}$ & $\begin{array}{l}6.1 \\
20 \\
10.9 \\
9.2 \\
8.6 \\
10.9\end{array}$ & $\begin{array}{l}154 \mathrm{Gd}(\mathrm{d}, 2 \mathrm{n}) \\
155 \mathrm{Gd}(\mathrm{d}, 3 \mathrm{n}) \\
156 \mathrm{Gd}(\mathrm{d}, 4 \mathrm{n}) \\
157 \mathrm{Gd}(\mathrm{d}, 5 \mathrm{n}) \\
158 \mathrm{Gd}(\mathrm{d}, 6 \mathrm{n}) \\
160 \mathrm{Gd}(\mathrm{d}, 8 \mathrm{n})\end{array}$ & $\begin{array}{l}-6556.6^{*} \\
-12991.8^{*} \\
-21528.1^{*} \\
-27888.0^{*} \\
-35825.4^{*} \\
-49220.1^{*}\end{array}$ \\
\hline $\begin{array}{l}154 m 2 \mathbf{T b} \\
\mathrm{e}^{+}+\mathrm{b}^{+}(98.2 \%) \\
\text { IT }(1.8 \%)\end{array}$ & $22.7 \mathrm{~h}$ & $\begin{array}{l}123.071 \\
225.94 \\
346.643 \\
1004.725 \\
1419.81\end{array}$ & $\begin{array}{l}43 \\
26.8 \\
69 \\
7.1 \\
46\end{array}$ & $\begin{array}{l}154 \mathrm{Gd}(\mathrm{d}, 2 \mathrm{n}) \\
155_{\mathrm{Gd}(\mathrm{d}, 3 \mathrm{n})} \\
156 \mathrm{Gd}(\mathrm{d}, 4 \mathrm{n}) \\
157 \mathrm{Gd}(\mathrm{d}, 5 \mathrm{n}) \\
158 \mathrm{Gd}(\mathrm{d}, 6 \mathrm{n}) \\
1{ }^{60} \mathrm{Gd}(\mathrm{d}, 8 \mathrm{n})\end{array}$ & $\begin{array}{l}-6556.6^{*} \\
-12991.8^{*} \\
-21528.1^{*} \\
-27888.0^{*} \\
-35825.4^{*} \\
-49220.1^{*}\end{array}$ \\
\hline $\begin{array}{l}{ }^{154 g} \mathbf{T b} \\
\varepsilon: 100 \%\end{array}$ & $21.5 \mathrm{~h}$ & $\begin{array}{l}123.07 \\
247.94 \\
557.60 \\
692.41 \\
704.90 \\
722.12 \\
873.21 \\
996.24 \\
1274.436 \\
1291.31\end{array}$ & $\begin{array}{l}26 \\
1.7 \\
5.4 \\
3.18 \\
4.8 \\
7.7 \\
5.3 \\
4.9 \\
10.5 \\
6.9\end{array}$ & $\begin{array}{l}154 \mathrm{Gd}(\mathrm{d}, 2 \mathrm{n}) \\
155 \mathrm{Gd}(\mathrm{d}, 3 \mathrm{n}) \\
156 \mathrm{Gd}(\mathrm{d}, 4 \mathrm{n}) \\
157 \mathrm{Gd}(\mathrm{d}, 5 \mathrm{n}) \\
158 \mathrm{Gd}(\mathrm{d}, 6 \mathrm{n}) \\
160 \mathrm{Gd}(\mathrm{d}, 8 \mathrm{n})\end{array}$ & $\begin{array}{l}-6556.6 \\
-12991.8 \\
-21528.1 \\
-27888.0 \\
-35825.4 \\
-49220.1\end{array}$ \\
\hline $\begin{array}{l}{ }^{153} \mathbf{T b} \\
\varepsilon: 100 \%\end{array}$ & $2.34 \mathrm{~d}$ & $\begin{array}{l}102.255 \\
109.758 \\
170.42 \\
212.00 \\
249.55\end{array}$ & $\begin{array}{l}6.4 \\
6.8 \\
6.3 \\
31.0 \\
2.33\end{array}$ & $\begin{array}{l}152 \mathrm{Gd}(\mathrm{d}, \mathrm{n}) \\
154 \mathrm{Gd}(\mathrm{d}, 3 \mathrm{n}) \\
155_{\mathrm{Gd}(\mathrm{d}, 4 \mathrm{n})} \\
156 \mathrm{Gd}(\mathrm{d}, 5 \mathrm{n}) \\
157 \mathrm{Gd}(\mathrm{d}, 6 \mathrm{n}) \\
{ }^{158} \mathrm{Gd}(\mathrm{d}, 7 \mathrm{n})\end{array}$ & $\begin{array}{l}1671.05 \\
-13470.62 \\
-19905.86 \\
-28442.21 \\
-34802.07 \\
-42739.46\end{array}$ \\
\hline $\begin{array}{l}152 \mathbf{T b} \\
\varepsilon: 100 \%\end{array}$ & $17.5 \mathrm{~h}$ & $\begin{array}{l}271.08 \\
344.28 \\
411.08 \\
586.29 \\
764.88 \\
778.86 \\
974.1 \\
1109.2 \\
1299.11 \\
\end{array}$ & $\begin{array}{l}8.6 \\
65 \\
4.1 \\
9.4 \\
2.9 \\
5.8 \\
3.1 \\
2.7 \\
2.15 \\
\end{array}$ & $\begin{array}{l}{ }^{152} \mathrm{Gd}(\mathrm{d}, 2 \mathrm{n}) \\
{ }^{154} \mathrm{Gd}(\mathrm{d}, 4 \mathrm{n}) \\
{ }^{155} \mathrm{Gd}(\mathrm{d}, 5 \mathrm{n}) \\
156 \mathrm{Gd}(\mathrm{d}, 6 \mathrm{n}) \\
{ }^{157} \mathrm{Gd}(\mathrm{d}, 7 \mathrm{n})\end{array}$ & $\begin{array}{l}-6996.9 \\
-22138.6 \\
-28573.8 \\
-37110.2 \\
-43470.0\end{array}$ \\
\hline $\begin{array}{l}{ }^{151} \mathbf{T b} \\
\alpha: 0.0095 \\
(0.0095 \%) \\
\varepsilon: 99.9905 \%\end{array}$ & $17.609 \mathrm{~h}$ & $\begin{array}{l}108.088 \\
180.186 \\
251.863 \\
287.357 \\
395.444 \\
443.879 \\
479.357 \\
587.46 \\
616.561 \\
731.227\end{array}$ & $\begin{array}{l}24.3 \\
11.5 \\
26.3 \\
28.3 \\
10.8 \\
10.8 \\
15.4 \\
15.6 \\
10.4 \\
7.7\end{array}$ & $\begin{array}{l}{ }^{152} \mathrm{Gd}(\mathrm{d}, 3 \mathrm{n}) \\
{ }^{154} \mathrm{Gd}(\mathrm{d}, 5 \mathrm{n}) \\
155 \mathrm{Gd}(\mathrm{d}, 6 \mathrm{n}) \\
{ }^{156} \mathrm{Gd}(\mathrm{d}, 7 \mathrm{n}) \\
{ }^{157} \mathrm{Gd}(\mathrm{d}, 8 \mathrm{n})\end{array}$ & $\begin{array}{l}-14161.58 \\
-29303.27 \\
-35738.5 \\
-44274.85 \\
-50634.71\end{array}$ \\
\hline
\end{tabular}


Table 3: Table 3 cont.

\begin{tabular}{|c|c|c|c|c|c|}
\hline $\begin{array}{l}\text { Nuclide } \\
\text { Decay mode }\end{array}$ & Half-life & $\mathrm{E}_{\gamma}(\mathrm{keV})$ & $\mathrm{I}_{\gamma}(\%)$ & Contributing reaction & $\begin{array}{l}\begin{array}{l}\text { Q-value } \\
(\mathrm{keV})\end{array} \\
\end{array}$ \\
\hline $\begin{array}{l}{ }^{159} \mathbf{G d} \\
\beta^{-}: 100 \%\end{array}$ & $18.479 \mathrm{~h}$ & 363.5430 & 11.78 & $\begin{array}{l}158 \mathrm{Gd}(\mathrm{d}, \mathrm{p}) \\
1{ }^{160} \mathrm{Gd}(\mathrm{d}, \mathrm{p} 2 \mathrm{n}) \\
{ }^{159} \mathrm{Eu} \text { decay }\end{array}$ & $\begin{array}{l}3718.644 \\
-9676.04\end{array}$ \\
\hline $\begin{array}{l}{ }^{153} \mathbf{G d} \\
\varepsilon: 100 \%\end{array}$ & $240.4 \mathrm{~d}$ & $\begin{array}{l}97.43100 \\
103.18012\end{array}$ & $\begin{array}{l}29.0 \\
21.1\end{array}$ & $\begin{array}{l}152 \mathrm{Gd}(\mathrm{d}, \mathrm{p}) \\
154 \mathrm{Gd}(\mathrm{d}, \mathrm{p} 2 \mathrm{n}) \\
155_{\mathrm{Gd}(\mathrm{d}, \mathrm{p} 3 \mathrm{n})} \\
{ }^{156} \mathrm{Gd}(\mathrm{d}, \mathrm{p} 4 \mathrm{n}) \\
{ }^{157} \mathrm{Gd}(\mathrm{d}, \mathrm{p} 5 \mathrm{n}) \\
{ }^{158} \mathrm{Gd}(\mathrm{d}, \mathrm{p} 6 \mathrm{n})\end{array}$ & $\begin{array}{l}4022.394 \\
-11119.3 \\
-17554.53 \\
-26090.88 \\
-32450.74 \\
-40388.13\end{array}$ \\
\hline $\begin{array}{l}{ }^{151} \mathbf{G d} \\
\varepsilon: 100 \% \\
\alpha: 0.8 \mathrm{E}-6 \%\end{array}$ & $123.9 \mathrm{~d}$ & $\begin{array}{l}153.60 \\
174.70 \\
243.29\end{array}$ & $\begin{array}{l}6.2 \\
2.96 \\
5.6\end{array}$ & $\begin{array}{l}{ }^{152} \mathrm{Gd}(\mathrm{d}, \mathrm{p} 2 \mathrm{n}) \\
{ }^{154} \mathrm{Gd}(\mathrm{d}, \mathrm{p} 4 \mathrm{n}) \\
{ }^{155} \mathrm{Gd}(\mathrm{d}, \mathrm{p} 5 \mathrm{n}) \\
{ }^{156} \mathrm{Gd}(\mathrm{d}, \mathrm{p} 6 \mathrm{n}) \\
{ }^{157} \mathrm{Gd}(\mathrm{d}, \mathrm{p} 7 \mathrm{n}) \\
{ }^{158} \mathrm{Gd}(\mathrm{d}, \mathrm{p} 8 \mathrm{n}) \\
{ }^{160} \mathrm{Gd}(\mathrm{d}, \mathrm{p} 10 \mathrm{n})\end{array}$ & $\begin{array}{l}-10814.23 \\
-25955.91 \\
-32391.15 \\
-40927.5 \\
-47287.36 \\
-55224.75 \\
X\end{array}$ \\
\hline $\begin{array}{l}{ }^{156} \mathbf{E u} \\
\beta^{-}: 100 \%\end{array}$ & $15.19 \mathrm{~d}$ & \begin{tabular}{l|}
646.29 \\
723.47 \\
811.77 \\
1079.16 \\
1153.67 \\
1154.08 \\
1230.71 \\
1242.42
\end{tabular} & $\begin{array}{l}6.3 \\
5.4 \\
9.7 \\
4.6 \\
6.8 \\
4.7 \\
8.0 \\
6.6\end{array}$ & $\begin{array}{l}156 \mathrm{Gd}(\mathrm{d}, 2 \mathrm{p}) \\
157_{\mathrm{Gd}(\mathrm{d}, 2 \mathrm{pn})} \\
158_{\mathrm{Gd}(\mathrm{d}, 2 \mathrm{p} 2 \mathrm{n})} \\
{ }^{160} \mathrm{Gd}(\mathrm{d}, 2 \mathrm{p} 4 \mathrm{n})\end{array}$ & $\begin{array}{l}-3891.35 \\
-10251.21 \\
-18188.6 \\
-31583.28\end{array}$ \\
\hline
\end{tabular}

The Q-values refer to formation of the ground state and are obtained fromthe Q-value calculation tool of Pritychenko et al. (Pritychenko and Sonzogni 20031. When complex particles are emitted instead of individual protons and neutrons the Q-values have to be decreased by the respective binding energies of the compound particles: $\mathrm{np}-\mathrm{d},+2.2 \mathrm{MeV} ; 2 \mathrm{np}-\mathrm{t},+8.48 \mathrm{MeV}$; $\mathrm{n} 2 \mathrm{p}-{ }^{3} \mathrm{He},+7.72 \mathrm{MeV} ; 2 \mathrm{n} 2 \mathrm{p}-\alpha,+28.30 \mathrm{MeV}$. *In case of ${ }^{154 m 1} \mathrm{~Tb}$ and ${ }^{154 m 2} \mathrm{~Tb}$ the Table 3 includes $\mathrm{Q}$ values of the ground state, because level energies of the isomeric states are not known.

Table 4: Experimental cross-sections of ${ }^{n a t} \mathrm{Gd}(\mathrm{d}, \mathrm{xn}){ }^{161,160,156(m+), 155,154 g, 154 m 1,154 m 2,153,152(m+), 151(m+)} \mathrm{Tb}$ reactions

\begin{tabular}{|c|c|c|c|c|c|c|c|c|c|c|c|c|c|c|c|c|c|c|c|c|c|}
\hline \multicolumn{2}{|c|}{$\begin{array}{l}\mathrm{E} \pm \Delta \mathrm{E} \\
(\mathrm{MeV})\end{array}$} & \multicolumn{20}{|c|}{$\begin{array}{l}\text { Cross-section }(\sigma) \pm \Delta \sigma \\
(\mathrm{mb})\end{array}$} \\
\hline & & \multicolumn{2}{|c|}{$161 \mathrm{~Tb}$ (cum) } & \multicolumn{2}{|c|}{${ }^{160} \mathrm{~Tb}$} & \multicolumn{2}{|c|}{${ }^{156} \mathrm{~Tb}(\mathrm{~m}+)$} & \multicolumn{2}{|c|}{$155 \mathrm{~Tb}$} & \multicolumn{2}{|c|}{${ }^{154 g_{\mathrm{Tb}}}$} & \multicolumn{2}{|c|}{${ }^{154 m 1} \mathrm{~Tb}$} & \multicolumn{2}{|c|}{${ }^{154 m 2} \mathrm{~Tb}$} & \multicolumn{2}{|c|}{${ }^{153} \mathrm{~Tb}$} & \multicolumn{2}{|c|}{${ }^{152} \mathrm{~Tb}(\mathrm{~m}+)$} & \multicolumn{2}{|c|}{${ }^{151} \mathrm{~Tb}(\mathrm{~m}+)$} \\
\hline 5.4 & 0.6 & 4.1 & 0.7 & 11.3 & 1.4 & 1.4 & 0.3 & 0.6 & 0.3 & 0.1 & 0.05 & & & & & & & & & & \\
\hline 8.4 & 0.5 & 139 & 16 & 303 & 33 & 33.1 & 4.0 & 32.8 & 4.1 & 0.6 & 0.1 & 1.8 & 0.2 & 2.6 & 0.4 & & & & & & \\
\hline 10.9 & 0.5 & 234 & 27 & 435 & 48 & 106.6 & 12 & 90.5 & 15.9 & 0.8 & 0.1 & 8.6 & 0.9 & 13.0 & 1.5 & & & & & & \\
\hline 13.0 & 0.4 & 200 & 23 & 531 & 58 & 144.1 & 16 & 139 & 22 & 0.9 & 0.1 & 15.4 & 1.7 & 23.4 & 2.6 & & & 0.11 & 0.016 & & \\
\hline 13.5 & 0.9 & 223 & 24 & 553 & 61 & 155.7 & 17 & 120 & 13 & & & 15.1 & 5.2 & & & & & & & & \\
\hline 14.9 & 0.4 & 144 & 17 & 346 & 38 & 180.1 & 20 & 140 & 19 & 1.9 & 0.2 & 27.6 & 3.0 & 42.5 & 4.7 & & & 0.73 & 0.087 & & \\
\hline 16.6 & 0.4 & 141 & 18 & 268 & 30 & 246.9 & 27 & 193 & 26 & 3.8 & 0.4 & 61.8 & 6.7 & 102 & 11 & 3.7 & 0.5 & 1.4 & 0.2 & 0.29 & 0.08 \\
\hline 18.3 & 0.3 & 132 & 18 & 191 & 22 & 252.7 & 28 & 195 & 26 & 6.8 & 0.8 & 93.9 & 10.2 & 138 & 15 & 8.0 & 1.0 & 1.7 & 0.2 & 0.38 & 0.18 \\
\hline 19.4 & 0.8 & 193 & 21 & 197 & 23 & 244.3 & 26 & 252 & 27 & 7.1 & 0.8 & 110 & 12 & 157 & 17 & 10.9 & 1.2 & & & & \\
\hline 19.8 & 0.3 & 116 & 21 & 144 & 17 & 236.8 & 26 & 211 & 28 & 9.1 & 1.0 & 118 & 13 & 174 & 19 & 13.3 & 1.5 & 1.6 & 0.2 & 0.17 & 0.04 \\
\hline 21.9 & 0.7 & 160 & 17 & 147 & 20 & 243.2 & 26 & 403 & 44 & 11.5 & 1.3 & 154 & 17 & 207 & 23 & 20.5 & 2.2 & & & & \\
\hline 24.2 & 0.7 & 147 & 16 & 132 & 18 & 244.4 & 26 & 329 & 36 & 14.4 & 1.6 & 169 & 18 & 210 & 23 & 30.7 & 3.4 & & & & \\
\hline 26.4 & 0.7 & 112 & 40 & 106 & 16 & 279.6 & 30 & 365 & 40 & 14.5 & 1.6 & 159 & 17 & 241 & 26 & 53.4 & 5.8 & & & & \\
\hline 28.4 & 0.6 & 104 & 11 & 108 & 17 & 313.1 & 34 & 360 & 39 & 18.3 & 2.0 & 189 & 21 & 271 & 30 & 91.1 & 9.9 & & & & \\
\hline 30.4 & 0.6 & 105 & 11 & 109 & 17 & 330.4 & 36 & 334 & 36 & 19.8 & 2.2 & 225 & 24 & 253 & 28 & 121 & 13 & 1.3 & 0.5 & & \\
\hline 32.2 & 0.6 & & & 80 & 15 & 337.2 & 37 & 324 & 35 & & & & & 268 & 35 & 146 & 16 & 5.9 & 0.7 & 0.64 & 0.24 \\
\hline 34.0 & 0.5 & & & 100 & 18 & 330.6 & 36 & 328 & 36 & 23.7 & 2.6 & 241 & 26 & 315 & 35 & 152 & 16 & 10.8 & 1.2 & & \\
\hline 35.7 & 0.5 & 83.4 & 9 & 74.2 & 19.1 & 298.2 & 32 & 334 & 36 & 26.3 & 2.9 & 261 & 28 & 310 & 34 & 165 & 18 & 17.8 & 2.0 & & \\
\hline 37.4 & 0.5 & 72.3 & 29 & 72.4 & $\begin{array}{l}13.6 \\
\end{array}$ & 263.7 & 29 & 351 & 38 & 28.6 & 3.1 & 283 & 31 & 319 & 35 & 180 & 20 & 29.9 & 3.3 & & \\
\hline 39.0 & 0.5 & & & 65.8 & 14.2 & 226.9 & 25 & 361 & 39 & 27.1 & 3.0 & 279 & 30 & 313 & 34 & 186 & 20 & 43.4 & 4.7 & 4.8 & 0.6 \\
\hline 40.5 & 0.4 & 77. & 8.3 & 48.7 & 12.4 & 203.6 & 22 & 366 & 40 & 30.5 & 3.3 & 303 & 33 & 323 & 36 & 215 & 23 & 57.1 & 6.2 & & \\
\hline 42.1 & 0.4 & & & 45.4 & 11.5 & 192.7 & 21 & 376 & 41 & 26.2 & 2.9 & 252 & 27 & 306 & 34 & 204 & 22 & 66.8 & 7.3 & 7.6 & 1.0 \\
\hline 43.6 & 0.4 & & & 52.2 & 10.1 & 192.6 & 21 & 372 & 40 & 25.0 & 2.7 & 249 & 27 & 298 & 33 & 214 & 23 & 74.8 & 8.1 & 11.6 & 1.4 \\
\hline 45.0 & 0.4 & 66.1 & 36.9 & 57.5 & 14.8 & 202.8 & 22 & 367 & 40 & 26.7 & 2.9 & 264 & 29 & 274 & 30 & 232 & 25 & 82.1 & 8.9 & 16.7 & 1.9 \\
\hline 46.4 & 0.3 & 76.1 & 15.8 & 52.2 & 6.3 & 207.0 & 22 & 332 & 36 & 25.2 & 2.8 & 249 & 27 & 283 & 31 & 227 & 25 & 84.0 & 9.1 & 21.7 & 2.4 \\
\hline 47.8 & 0.3 & & & $\begin{array}{l}52.9 \\
\end{array}$ & 13.0 & 226.3 & 25 & 320 & 35 & \begin{tabular}{|l|}
24.1 \\
\end{tabular} & 2.6 & 226 & 24 & 307 & 34 & 213 & 23 & 96.3 & 10.4 & 30.2 & 3.3 \\
\hline 49.2 & 0.3 & & & 49.6 & 8.4 & 230.6 & 25 & 285 & 31 & 26.5 & 2.9 & 252 & 27 & 286 & 31 & 232 & 25 & 98.2 & 10.6 & 34.6 & 3.8 \\
\hline
\end{tabular}


Table 5: Experimental cross-sections of ${ }^{n a t} \mathrm{Gd}(\mathrm{d}, \mathrm{x}){ }^{159,153,151} \mathrm{Gd}$ and ${ }^{\text {nat }} \mathrm{Gd}(\mathrm{d}, \mathrm{x}){ }^{156}$ Eu reactions

\begin{tabular}{|c|c|c|c|c|c|c|c|c|c|}
\hline \multirow{2}{*}{\multicolumn{2}{|c|}{$\begin{array}{l}\mathrm{E} \pm \Delta \mathrm{E} \\
(\mathrm{MeV})\end{array}$}} & \multicolumn{8}{|c|}{$\begin{array}{l}\text { Cross-section }(\sigma) \pm \Delta \sigma \\
(\mathrm{mb})\end{array}$} \\
\hline & & \multicolumn{2}{|c|}{${ }^{159} \mathrm{Gd}$} & \multicolumn{2}{|c|}{${ }^{153} \mathrm{Gd}$} & \multicolumn{2}{|c|}{${ }^{151} \mathrm{Gd}$} & \multicolumn{2}{|c|}{${ }^{156} \mathrm{Eu}$} \\
\hline 5.4 & 0.6 & 4.37 & 0.49 & & & & & & \\
\hline 8.4 & 0.5 & 25.5 & 2.8 & & & & & & \\
\hline 10.9 & 0.5 & 70.0 & 7.6 & & & & & & \\
\hline 13.0 & 0.4 & 63.5 & 6.9 & & & & & & \\
\hline 13.5 & 0.9 & 61.0 & 6.6 & & & & & & \\
\hline $\begin{array}{l}4.9 \\
\end{array}$ & 0.4 & 57.8 & 6.3 & & & & & & \\
\hline 16.6 & 0.4 & 48.7 & 5.3 & & & & & & \\
\hline 18.3 & 0.3 & 41.3 & 4.5 & & & & & & \\
\hline 19.4 & 0.8 & 43.9 & 4.8 & & & & & & \\
\hline 19.8 & 0.3 & 39.2 & 4.3 & & & & & 1.74 & 0.76 \\
\hline 21.9 & 0.7 & 44.8 & 4.9 & 59.3 & 7.8 & & & & \\
\hline 24.2 & 0.7 & 48.2 & 5.3 & & & & & & \\
\hline 26.4 & 0.7 & 53.2 & 5.8 & 70.8 & 9.3 & & & & \\
\hline 28.4 & 0.6 & 62.6 & 6.8 & 127 & 16 & & & & \\
\hline 30.4 & 0.6 & 67.8 & 7.4 & 191 & 24 & & & & \\
\hline 32.2 & 0.6 & 70.4 & 7.5 & 227 & 29 & & & 2.05 & 0.78 \\
\hline 34.0 & 0.5 & 68.1 & 7.5 & 303 & 39 & & & & \\
\hline 35.7 & 0.5 & 66.2 & 7.3 & 256 & 33 & & & & \\
\hline 37.4 & 0.5 & 70.2 & 7.7 & 343 & 44 & & & 1.87 & 0.58 \\
\hline 39.0 & 0.5 & 72.1 & 7.9 & 293 & 37 & & & & \\
\hline 40.5 & 0.4 & 67.8 & 7.4 & 315 & 40 & & & 2.09 & 0.69 \\
\hline 42.1 & 0.4 & 65.0 & 7.1 & 356 & 45 & & & & \\
\hline 43.6 & 0.4 & 61.1 & 6.7 & 293 & 37 & 9.3 & 1.5 & 3.29 & 0.65 \\
\hline 45.0 & 0.4 & 61.4 & 6.8 & 398 & 51 & 17.2 & 2.8 & 3.54 & 0.78 \\
\hline 46.4 & 0.3 & 56.7 & 6.2 & 444 & 57 & 19.3 & 3.5 & 1.62 & 0.25 \\
\hline 47.8 & 0.3 & 52.1 & $\begin{array}{l}5.7 \\
5.7\end{array}$ & 474 & 60 & 35.8 & 5.7 & & \\
\hline 49.2 & 0.3 & 52.1 & 5.7 & 463 & 59 & 44.9 & 5.3 & 3.49 & 0.54 \\
\hline
\end{tabular}

Table 6: Main light ion induced reactions for direct and indirect production of the ${ }^{153} \mathrm{Gd}$

\begin{tabular}{|l|l|l|l|l|}
\hline Reaction & Energy range (MeV) & $\begin{array}{l}\text { Yield } \\
(\mathrm{MBq} / \mathrm{C})\end{array}$ & $\begin{array}{l}\text { Disturbing reaction } \\
(\mathrm{MeV})\end{array}$ \\
\hline$\left.{ }^{153} \mathrm{Eu}(\mathrm{p}, \mathrm{n})\right)^{153} \mathrm{Gd}$ & 52 & ${ }^{153} \mathrm{Eu}(\mathrm{p}, 3 \mathrm{n})^{151} \mathrm{Gd}$ & 16.2 \\
\hline${ }^{153} \mathrm{Eu}(\mathrm{d}, 2 \mathrm{n})^{153} \mathrm{Gd}$ & $16-6$ & 188 & ${ }^{153} \mathrm{Eu}(\mathrm{d}, 4 \mathrm{n})^{151} \mathrm{Gd}$ & 18.6 \\
\hline${ }^{154} \mathrm{Gd}(\mathrm{p}, 2 \mathrm{n})^{153} \mathrm{~Tb} \longrightarrow{ }^{153} \mathrm{Gd}$ & $19-7$ & 651 & ${ }^{154} \mathrm{Gd}(\mathrm{p}, 4 \mathrm{n})^{151} \mathrm{~Tb}$ & 27.3 \\
\hline${ }^{154} \mathrm{Gd}(\mathrm{d}, 3 \mathrm{n})^{153} \mathrm{~Tb} \longrightarrow{ }^{153} \mathrm{Gd}$ & $27-12$ & ${ }^{154} \mathrm{Gd}(\mathrm{d}, 5 \mathrm{n})^{151} \mathrm{~Tb}$ & 29.7 \\
\hline${ }^{151} \mathrm{Eu}(\alpha, 2 \mathrm{n})^{153} \mathrm{~Tb} \longrightarrow{ }^{153} \mathrm{Gd}$ & $30-15$ & ${ }^{151} \mathrm{Eu}(\alpha, 4 \mathrm{n})^{151} \mathrm{~Tb}$ & 33.8 \\
\hline${ }^{151} \mathrm{Eu}\left({ }^{3} \mathrm{He}, \mathrm{n}\right)^{153} \mathrm{~Tb} \rightarrow{ }^{153} \mathrm{Gd}$ & $34-19$ & 31 & ${ }^{151} \mathrm{Eu}\left({ }^{3} \mathrm{He}, 3 \mathrm{n}\right)^{151} \mathrm{~Tb}$ & 12.6 \\
\hline
\end{tabular}




\section{References}

Andersen, H. H., Ziegler, J. F., 1977. Hydrogen stopping powers and ranges in all elements. The Stopping and ranges of ions in matter, Volume 3. The Stopping and ranges of ions in matter. Pergamon Press, New York.

Beyer, G. J., Ruth, T. J., 2003. The role of electromagnetic separators in the production of radiotracers for bio-medical research and nuclear medical application. Nuclear Instruments \& Methods in Physics Research Section B-Beam Interactions with Materials and Atoms 204, 694-700.

Bonardi, M., 1987. The contribution to nuclear data for biomedical radioisotope production from the milan cyclotron facility.

Canberra, 2000. http://www.canberra.com/products/radiochemistry_lab/genie-2000-software.asp.

Case, F. N., Acree, E. H., Cutshal, N. H., 1969. Production study of gadolinium-153. Tech. rep.

Dityuk, A. I., Konobeyev, A. Y., Lunev, V. P., Shubin, Y. N., 1998. New version of the advanced computer code alice-ippe. Tech. rep., IAEA.

Dmitriev, P. P., Krasnov, N. N., Molin, G. A., 1982. Radioactive nuclide yields for thick target at $22 \mathrm{mev}$ deuterons energy. Yadernie Konstanti 34 (4), 38.

Dmitriev, P. P., Molin, G. A., Dmitrieva, Z. P., 1989. Production of tb-155 for nuclear-medicine in the reactions gd-155(pn), gd-156(p2n), and gd-155(d2n). Soviet Atomic Energy 66 (6), 470-472.

Ekstrm, L. P., Firestone, R. B., 1999. Www table of radioactive isotopes, database version $2 / 28 / 99$.

Herman, M., Capote, R., Carlson, B. V., Oblozinsky, P., Sin, M., Trkov, A., Wienke, H., Zerkin, V., 2007. Empire: Nuclear reaction model code system for data evaluation. Nuclear Data Sheets 108 (12), 2655-2715.

Hermanne, A., Rebeles, R. A., Tárkányi, F., Takács, S., Takács, M. P., Csikai, J., Ignatyuk, A., 2012. Cross sections of deuteron induced reactions on sc-45 up to 50 mev: Experiments and comparison with theoretical codes. Nuclear Instruments \& Methods in Physics Research Section B-Beam Interactions with Materials and Atoms 270, 106-115.

Ignatyuk, A. V., 2011. Phenomenological systematics of the (d,p) cross sections, http://wwwnds.iaea.org/fendl3/000pages/rcm3/slides//ignatyuk_fendl3

International-Bureau-of-Weights-and-Measures, 1993. Guide to the expression of uncertainty in measurement, 1st Edition. International Organization for Standardization, Genve, Switzerland.

Kinsey, R. R., Dunford, C. L., Tuli, J. K., Burrows, T. W., 1997. Nudat 2.6. In: Proceedings of the 9th International Symposium on Capture Gamma Ray Spectroscopy and Related Topics. Vol. 2. Springer Hungarica Ltd, p. 657.

Koning, A. J., Rochman, D., 2012. Modern nuclear data evaluation with the talys code system. Nuclear Data Sheets 113, 2841.

Koning, A. J., Rochman, D., van der Marck, S., Kopecky, J., Sublet, J. C., Pomp, S., Sjostrand, H., Forrest, R., Bauge, E., Henriksson, H., 2012. Tendl-2012: Talysbased evaluated nuclear data library.

Liu, Y., Solomon, M., Achilefu, S., 2013. Perspectives and potential applications of nanomedicine in breast and prostate cancer. Medicinal Research Reviews 33 (1), 3-32.

Müller, C., Zhernosekov, K., Kster, U., Johnston, K., Dorrer, H., Hohn, A., van der Walt, N. T., Trler, A., Schibli, R., 2012. A unique matched quadruplet of terbium radioisotopes for pet and spect and for - and -radionuclide therapy: An in vivo proof-of-concept study with a new receptor-targeted folate derivative. The Journal of $\mathrm{Nu}$ clear Medicine 53 (12), 1951-1959.

NuDat, 2011. Nudat2 database http://www.nndc.bnl.gov/nudat2/.

Pritychenko, B., Sonzogni, A., 2003. Q-value calculator.

Rastrepina, G., 2009. Half life measurements of the ${ }^{154} t b$ isotope. Uzhhorod University Scientific Herald. Series Physics. 24, 171-174. 
Smith, M. A., Sutton, D., Tothill, P., 1983. Comparison between gd-153 and am-241, cs-137 for dual-photon absorptiometry of the spine. Physics in Medicine and Biology 28 (6), 709-721.

Székely, G., 1985. Fgm - a flexible gamma-spectrum analysis program for a small computer. Computer Physics Communications 34 (3), 313-324.

Tárkányi, F., Hermanne, A., Király, B., Takács, S., Ditrói, F., Baba, M., Ohtsuki, T., Kovalev, S. F., Ignatyuk, A. V., 2007. Study of activation cross-sections of deuteron induced reactions on erbium: Production of radioisotopes for practical applications. Nuclear Instruments \& Methods in Physics Research Section BBeam Interactions with Materials and Atoms 259 (2), 829-835.

Tárkányi, F., Hermanne, A., Takács, S., Ditrói, F., Csikai, J., Ignatyuk, A. V., 2013. Cross-section measurement of some deuteron induced reactions on $160 \mathrm{gd}$ for possible production of the therapeutic radionuclide 161tb. Journal of Radioanalytical and Nuclear Chemistry DOI 10.1007/s10967-013-2507-x.

Tárkányi, F., Szelecsényi, F., Takács, S., 1991. Determination of effective bombarding energies and fluxes using improved stacked-foil technique. Acta Radiologica, Supplementum 376, 72.

Tárkányi, F., Takács, S., Gul, K., Hermanne, A., Mustafa, M. G., Nortier, M., Oblozinsky, P., Qaim, S. M., Scholten, B., Shubin, Y. N., Youxiang, Z., 2001. Beam monitor reactions (chapter 4). charged particle crosssection database for medical radioisotope production: diagnostic radioisotopes and monitor reactions. Tech. rep., IAEA.

Van Laere, K., Koole, M., Kauppinen, T., Monsieurs, M., Bouwens, L., Dierck, R., 2000. Nonuniform transmission in brain spect using 201tl, 153gd, and 99mtc static line sources: anthropomorphic dosimetry studies and influence on brain quantification. Journal of Nuclear Medicine 41 (12), 2051-62.

Wadas, T. J., Sherman, C. D., Miner, J. H., Duncan, J. R., Anderson, C. J., 2010. The biodistribution of [gd153]gd-labeled magnetic resonance contrast agents in a transgenic mouse model of renal failure differs greatly from control mice. Magnetic Resonance in Medicine 64 (5), 1274-1280.

West, H. I., Lanier, R. G., Mustafa, M. G., Nuckolls, R. N., Frehaut, J., Adam, A., Philis, C. A., 1993. Proton and deutron excitation functions for eu-151. Tech. rep. 